\title{
Avaliação de desempenho do processo de orçamento: estudo de caso em uma obra de construção civil
}

\author{
Performance evaluation of the cost estimating process: \\ case study on a construction project
}

\section{Rogério Cabral Azevedo Departamento de Engenharia Civil Centro Federal de Educação Tecnológica de Minas Gerais Av. Amazonas, 7675 , Prédio 12 , Nova Gameleira
Belo Horizonte - MG - Brasil CEP $30510-000$ Tel.: (31) 3319-6822 E-mail: cabral.razevedo@gmail.com} Leonardo Ensslin
Depto. de Engenharia de Produção
Universidade Federal de Santa
Catarina
Campus Universitário Trindade
Caixa-Postal: 476
Florianópolis - SC - Brasil
CEP 88040-900

Tel.: (48) 331-7022 Ramal: 7022 E-mail: leonardoensslin@gmail.com

Rogério Tadeu de Oliveira Lacerda Depto. de Engenharia de Produção Universidade Federal de Santa Catarina

Florianópolis - SC - Brasil CEP $88040-900$ Tel.: (48) 9911-9374

E-mail: rogerlacerda@gmail.com

Lisiane Anderson França Depto. de Engenharia de Produção Universidade Federal de Santa Catarina Tel.: (047) 9604-6904 E-mail: lisianefranca@yahoo.com.br

Cindy Johanna Ibarra González Depto. de Engenharia de Produção Universidade Federal de Santa Tel.: (48) $\begin{array}{r}\text { Catarina } \\ 3721-9719\end{array}$ E-mail: cjibarra03@hotmail.com

Antônio Edésio Jungles Depto. de Engenharia de Civil Universidade Federal de Santa Tel.: (48) 3721-9050 E-mail: ajungles@gmail.com

Sandra Rolim Ensslin Depto. de Engenharia de Produção Universidade Federal de Santa Tel.: (48) 3721-6608 E-mail: sensslin@gmail.com Catarina
$721-6608$
gmail.com

Recebido em 03/12/2010 Aceito em 11/03/2011 management.

\section{Rogério Cabral Azevedo \\ Leonardo Ensslin \\ Rogério Tadeu de Oliveira Lacerda \\ Lisiane Anderson França \\ Cindy Johanna Ibarra González \\ Antônio Edésio Jungles \\ Sandra Rolim Ensslin}

Construtivista (MCDA-C), a qual permitiu identificar, organizar, mensurar e integrar os fatores necessários e suficientes, quando da avaliação de um orçamento, segundo a percepção do decisor em questão. O trabalho faz uma revisão de literatura sobre avaliação de desempenho e o gerenciamento de projetos no contexto de obras de construção civil. É apresentado o desenvolvimento do modelo construído para apoio à decisão, o qual permitiu ao gerente de engenharia avaliar o desempenho de um orçamento, identificando os fatores que causam desvios, a fim de eliminar ou minimizar suas causas, além de servir de base para propostas de melhorias no processo de orçamentação.

Palavras-chave: Avaliação de desempenho. MCDA-C. Orçamentação. Construção civil. Gerenciamento de projetos.

\section{Abstract}

The aim of this paper is propose a model for evaluating the cost estimating process in construction. It is an exploratory research study based on a case study carried out in a Brazilian construction company. The intervention tool used was the Constructivist Multicriteria Decision Support Methodology, which enabled the identification, organization, measuring and integration of the necessary and sufficient factors for evaluating a budget, according to the perception of the decision-maker. This paper presents a literature review on performance evaluation and project management in the context of the construction industry. The development of the model for supporting decision making is presented-this allowed the engineering manager to evaluate the performance of the cons estimating process, identifying factors that cause deviations, in order to eliminate or minimize their causes, and to provide a basis for proposals of improvements in the cost estimating process.

Keywords: Performance evaluation. MCDA-C. Cost estimating. Construction. Project 


\section{Introdução}

A construção civil é uma atividade econômica que representa uma parcela importante do produto interno bruto de qualquer país e tem efeitos significativos na empregabilidade de pessoal (UNIEMP, 2010). Tal segmento econômico é uma atividade em que seu produto representa um grande investimento, tanto para as empresas quanto para seus clientes.

Por esse motivo, o processo de orçar um empreendimento torna-se fator crítico para empresas construtoras antes que a edificação seja projetada em detalhes e que os contratos de venda e de fornecimento sejam firmados.

Com uma investigação em custos criteriosa, podese reduzir desvios que impactam na lucratividade do empreendimento ou até mesmo desvios significantes, que poderiam inviabilizar a continuidade da execução de uma obra (LOPES; LIBRELOTTO; AVILA, 2003; TAS; YAMAN, 2005).

Para atender a tal investigação, três metodologias para elaboração de estimativas de custos se destacam no contexto brasileiro: o Custo Unitário Básico (CUB), o Modelo Paramétrico de Custo e o Orçamento Detalhado (OTERO, 1998; MARCHIORI, 2009). As duas primeiras se destinam às etapas iniciais do empreendimento (estudo de viabilidade e planejamento inicial), e a terceira, às etapas de projeto e desenvolvimento, quando informações sobre quantitativos já podem ser determinadas.

No entanto, esses métodos de elaboração de orçamentos têm apresentado limitações nos contextos atuais, uma vez que os projetos se tornam cada vez mais amplos, multinacionais e sofisticados (TAS; YAMAN, 2005).

As principais limitações encontradas na literatura são: a falta de precisão, de pontualidade e a pouca periodicidade na atualização das informações de custo; o formato excessivamente voltado às exigências legais, fiscais e acionárias; e a falta de um foco gerencial na elaboração dos custos (LOPES; LIBRELOTTO; AVILA, 2003; KERN; FORMOSO, 2006; MARCHIORI; UBIRACI, 2006; LIU; ZHU, 2007; MARCHIORI, 2009).

Ante essa constatação, diversos trabalhos têm sido desenvolvidos com o intuito de aumentar a precisão das estimativas de custo e seu potencial como base para a tomada de decisão (TAS; YAMAN, 2005; KERN; FORMOSO, 2006; KERN; SOARES; FORMOSO, 2006; MARCHIORI; UBIRACI, 2006; LIU; ZHU, 2007;
MARCHIORI, 2009; JACOMIT; GRANJA, 2010).

Com vistas a contribuir para esse contexto em evolução, este artigo relata uma nova abordagem para lidar com esse problema de orçamentação em projetos de construção civil e apresenta um estudo de caso realizado em uma construtora catarinense, onde foi aplicada a metodologia de apoio à decisão multicritério construtivista (MCDA-C) (ENSSLIN et al., 2010; MORAES et al., 2010; ZAMCOPÉ et al., 2010; LACERDA; ENSSLIN; ENSSLIN, 2011a, 2011b).

As atividades preconizadas pela MCDA-C permitiram ao gerente da construtora identificar, organizar e mensurar os aspectos que influenciam os desvios em custos, possibilitando atuar sobre suas causas, a fim de minimizá-las ou até eliminálas.

Esse conhecimento foi então organizado em um modelo multicritério que está sendo utilizado como guia para a geração de ações de melhorias e a avaliação dessas proposições, a fim de apoiar as decisões na organização estudada.

Além dessa introdução, o artigo está disposto em mais seis seções. Na seção seguinte, está contida a fundamentação teórica sobre avaliação de desempenho na construção civil; na terceira, encontra-se a metodologia de pesquisa; a quarta seção apresenta os procedimentos para a construção do modelo; a quinta seção se destina às considerações finais; e na última seção são listadas as referências bibliográficas.

\section{Referencial teórico}

\section{Gerenciamento de projetos de construção civil: contextualização}

Com o crescimento do setor da construção civil, dada a grande demanda provida pelo mercado, as empresas passaram a dar maior importância às práticas de gerenciamento de projetos para apoiar a tomada de decisão estratégica, melhorar a qualidade de suas obras e sua competitividade (WINTER; CHECKLAND, 2003).

Um projeto de construção civil possui algumas características que requerem um considerável esforço para executar um gerenciamento adequado:

(a) mobilização de grande quantidade de recursos especializados (WALKER, 2007); 
(b) executado em ambiente dinâmico, incerto e complexo, que envolve a maioria dos projetos de construção (KERN; FORMOSO, 2006);

(c) complexidade na avaliação do grau de risco do projeto (LIU; ZHU, 2007; ZENG; AN; SMITH, 2007); e

(d) envolvimento de muitos stakeholders, com posicionamentos diferentes ou até conflitantes (HOFFMANN; PROCOPIAK; ROSSETTO, 2008; YANG; PENG, 2008).

Perante essas características, o segmento da construção civil vem realizando esforços na busca por elevação de seus patamares de qualidade de produtos e serviços, obtenção de maior conformidade, confiabilidade e atendimento às necessidades dos clientes (PBQP-H, 2005).

Esses desafios requerem das construtoras um planejamento baseado em informações confiáveis. Sem uma estimativa de custo adequadamente detalhada, não há como prever resultados, independentemente da competência da gestão e dos recursos do contratante (LIU; ZHU, 2007).

Informações sólidas e confiáveis possibilitam uma gestão de custos eficiente, que, segundo Kern e Formoso (2006), devem ser dinâmicas, pró-ativas e capazes de suportar diferentes processos decisórios, a fim de proteger a empresa contra os efeitos nocivos da incerteza. O objetivo principal do planejamento deve ser a geração de informações para apoio à decisão (KERN; FORMOSO, 2006).

Essas informações são analisadas, organizadas e compiladas em um orçamento, que representa a formalização dos planos de projeto estabelecidos.

Esse é um grande desafio para as empresas, pois, apesar de os diversos processos construtivos poderem ser considerados repetitivos, cada empreendimento é único, em termos de projetos, condições locais, estrutura organizacional e cadeia de suprimentos (COSTA et al., 2006).

Dessa forma, o processo de orçamentação na construção civil reside em um contexto complexo, conflituoso e incerto (LACERDA; ENSSLIN; ENSSLIN, 2011b):

(a) complexo, por envolver múltiplos critérios não claramente explicitados e integrados por compensações não bem estabelecidas;

(b) conflituoso, por se tratar de um contexto onde distintos grupos de atores buscam melhorar o alcance dos critérios por eles percebidos como importantes em contraponto a outros critérios defendidos por outros grupos; e (c) incerto, por usar dados tanto qualitativos como quantitativos sem a preocupação da acuracidade que outras ciências poderiam disponibilizar.

Ou seja, um contexto onde os decisores reconhecem suas limitações quando do entendimento das consequências de suas decisões operacionais. Tais decisões têm, em seu propósito, a redução ou a eliminação de uma discrepância em um ou mais aspectos julgados pelo decisor como relevantes quando de sua avaliação do contexto (ROY, 1996).

Dessa forma, torna-se relevante analisar qual o conceito de avaliação de desempenho empregado pela literatura sobre gestão de projetos na construção civil.

\section{Avaliação de desempenho}

A avaliação de desempenho é, hoje, um processo que está inserto no contexto das organizações, independentemente de seu tipo ou finalidade. O processo de avaliar o desempenho permite a geração do conhecimento para que a tomada de decisão seja realizada de forma coerente com os valores e preferências dos gestores, os quais podem a qualquer momento alterar essa situação, aqui denominados decisores.

Assim, entre os artigos selecionados para compor o cerne do referencial bibliográfico da pesquisa, buscaram-se os conceitos acerca de avaliação de desempenho (AD):

(a) Kaplinski (2008) menciona que os métodos para auxiliar a tomada de decisão têm sido desenvolvidos dinamicamente e existe uma dependência evidente de novas e sofisticadas tecnologias de informação para auxiliar neste processo;

(b) para Cioffi e Khamooshi (2009), a avaliação de desempenho deve ser baseada na mensuração de riscos de experiências anteriores e em um modelo matemático que, a partir desse histórico, possa determinar a probabilidade e os valores associados a riscos de projetos futuros;

(c) Pollack-Johnson e Liberatore (2006) explicitam que a avaliação de desempenho deve mensurar a duração e o custo da tarefa, e também levar em consideração o critério de qualidade de execução dessas tarefas;

(d) Farris et al. (2006) entendem a avaliação de desempenho como uma atividade que deve permitir que o departamento ganhe novas visões sobre o impacto das mudanças em seu processo de engenharia em relação à duração do projeto, mediante a utilização de um índice que 
simultaneamente considera a duração do projeto e as variáveis de entrada;

(e) para Koo et al. (2010), a avaliação de desempenho deve permitir melhorar a competitividade da indústria da construção, através da utilização de informações mais precisas sobre os fatores críticos, tal como o custo da construção, já nas fases iniciais de um projeto de construção;

(f) para Fan, Lin e Sheu (2008), essa atividade contempla a avaliação das variáveis dos riscos relevantes do projeto, visando decidir ações de resposta para mitigá-los em um nível aceitável; e

(g) Banaitiene et al. (2008) entendem a avaliação de desempenho como uma atividade baseada em uma metodologia multicritério para apoiar o cliente, investidor ou contratante na avaliação e seleção de alternativas do ciclo de vida de um edifício, através de critérios qualiquantitativos.

Valendo-se dos conceitos apregoados pelos autores supracitados, os autores do presente trabalho expandem a abrangência da $\mathrm{AD}$ na gestão das organizações ao levarem em conta o seguinte conceito sobre Avaliação de Desempenho:

Avaliação de Desempenho é o processo para construir conhecimento no decisor, a respeito do contexto específico que se propõe avaliar, a partir da percepção do próprio decisor por meio de atividades que identificam, organizam, mensuram ordinalmente e cardinalmente, e sua integração e os meios para visualizar o impacto das ações e seu gerenciamento. (ENSSLIN, 2009).

A análise desse conceito permitiu extrair as lentes de pesquisa pelas quais a revisão da literatura foi executada, detalhadas nas cinco subseções seguintes.

\section{Identificação dos aspectos relevantes}

A identificação do que é relevante para o decisor, dentro do contexto avaliado, é o primeiro item de análise extraído do conceito exposto. A revisão da literatura nos apresenta diferentes processos sendo utilizados para identificar o que é relevante.

Cioffi e Khamooshi (2009) tratam os riscos ou falhas ocorridos em projetos já executados como aspectos relevantes, sem, contudo, explicitá-los em seu trabalho. Já para Pollack-Johnson e Liberatore (2006), a qualidade, o custo e o tempo de execução de cada etapa de um projeto são os aspectos relevantes a serem considerados, independentemente do contexto a ser avaliado.

De forma similar, Koo et al. (2010) utilizam um modelo de avaliação no qual a identificação dos aspectos relevantes é baseada em dados históricos e utilizada para determinar a similaridade entre projetos, auxiliando os stakeholders a estimar o orçamento de um projeto na fase inicial do planejamento de negócios.

Para Fan, Lin e Sheu (2008), os aspectos relevantes são associados a eventos de risco, identificados por meio da experiência em outros projetos e referências bibliográficas, devendo ser avaliados de modo desdobrado em três parâmetros ou dimensões:

(a) controlabilidade do risco do projeto;

(b) custos do gerenciamento do risco; e

(c) características do projeto.

Uma ampliação do contexto é obtida por Farris et al. (2006) e Kaplinski (2008). Farris et al. (2006) identificaram os aspectos relevantes por meio de consultas aos gestores responsáveis, nos aspectos apresentados pela ferramenta DEA (Data Envelopment Analysis) e em revisões da literatura de gerenciamento de projetos. Já Kaplinski (2008) buscou envolver os profissionais de engenharia civil e gerenciamento de construções na identificação dos aspectos relevantes, por meio de questionários aplicados a esses profissionais, em 2000 e 2005, na Polônia.

Uma evolução desse conceito é encontrada no trabalho de Banaitiene et al. (2008), em que se buscou a identificação dos aspectos relevantes nas preferências dos clientes e opinião de especialistas - incluindo proprietários, investidores e contratantes -, levantadas em reuniões e também em referências bibliográficas sobre o assunto.

A metodologia MCDA-C, adotada neste trabalho, considera que a identificação dos aspectos relevantes deve ser realizada sob a perspectiva do decisor, retratando o que é importante para ele no contexto avaliado. Assim, o próprio decisor deve estar envolvido nesse processo para que os resultados obtidos nessa identificação estejam de acordo com seus objetivos estratégicos.

\section{Mensuração dos aspectos relevantes}

Após a identificação dos aspectos considerados relevantes para o decisor, a forma de mensuração desses aspectos constitui o segundo item de análise trabalhado.

No trabalho de Kaplinski (2008) não se observa, explicitamente, o uso de escalas, mas, por suas colocações, supõe-se o uso de escalas ordinais para mensurar os aspectos relevantes.

Já para Cioffi e Khamooshi (2009) e Fan et al. (2008), a mensuração dos aspectos relevantes é feita por escalas ordinais, sendo a probabilidade mensurada com escalas de Likert, e seus impactos, 
por escalas ordinais, explicitando os valores financeiros comprometidos se o risco ocorrer.

Koo et al. (2010), Banaitiene et al. (2008) e Farris et al. (2006) utilizam-se de escalas ordinais para mensuração dos aspectos relevantes, porém se valem tanto de escalas que mensuram as propriedades físicas do contexto quanto de escalas de Likert.

Usando outra forma de mensuração, PollackJohnson e Liberatore (2006) utilizam-se de escalas cardinais para mensurar os objetivos, associando essas escalas cardinais às propriedades físicas do contexto.

O presente estudo se apóia na construção de descritores para explicitar o desempenho dos aspectos julgados como relevantes pelo decisor, valendo-se de escalas primeiramente ordinais que atendam às seguintes propriedades (ENSSLIN, 2009):

(a) mensurabilidade;

(b) operacionalidade;

(c) homogeneidade;

(d) inteligibilidade;

(e) distinção entre o desempenho melhor e o pior; e

(f) respeito às propriedades das escalas ordinais.

Reconhecendo os limites de uso das escalas ordinais, o presente trabalho se apóia em processos científicos para agregar as informações requeridas para transformar tais escalas em escalas cardinais e, dessa forma, ampliar o entendimento do contexto em comparar determinado nível de desempenho em dado critério com o mesmo nível de desempenho em outro indicador de desempenho.

Com esse conhecimento que as escalas cardinais proporcionam, tem-se a oportunidade de apresentar um processo cujas escalas de mensuração possam ser integradas e, ao mesmo tempo, respeitar os limites das escalas ordinais, utilizando-as apenas para operações matemáticas de frequência, contagem, mediana e moda (BARZILAI, 2001).

\section{Integração das escalas}

A integração das escalas objetiva propiciar uma visão global do contexto avaliado. Assim, seguindo em uma linha evolutiva, temos que Kaplinski (2008) não menciona a integração de escalas, sendo seu trabalho desenvolvido sem a explicitação de escalas de mensuração.

Já para Cioffi e Khamooshi (2009), a integração é realizada por meio da razão entre a soma das escalas ordinais pelo número máximo de eventos previstos, gerando uma média ponderada. Isso denota o uso de operações matemáticas com escalas ordinais, não reconhecendo, assim, suas limitações quanto a esse uso.

Nos trabalhos seguintes, a integração das escalas é propiciada por meio de outras formulações matemáticas, sendo no método apresentado por Farris et al. (2006) a integração feita através do emprego da ferramenta DEA (Data Envelopment Analysis), que, por meio de grupos de comparação de cada projeto com seus pares similares, determina, por meio de análises estatísticas, a variável de saída, no caso estudado, a duração do projeto.

De forma similar, Fan, Lin e Sheu (2008) o fazem pela aplicação de funções que consideram as variáveis de risco históricas utilizadas na avaliação, de forma a estimar o custo final do risco associado ao projeto avaliado.

A aplicação de pesos para compensação da contribuição de cada aspecto é encontrada em Koo et al. (2010) e Banaitiene et al. (2008). Em Koo et al. (2010), a integração das escalas, visando determinar a similaridade de projetos, utiliza pesos atribuídos por algoritmos genéticos (GA) para compensação dos aspectos relevantes e, para Banaitiene et al. (2008), a integração é realizada por meio de uma matriz de normalização que considera os valores de cada aspecto e seu peso, determinados pela preferência do decisor.

Embora o uso de taxas de compensação (pesos) para integração de escalas seja considerado como uma evolução no contexto da integração, ambos os estudos (BANAITIENE et al., 2008; KOO et al., 2010) o fazem sem associar essas taxas a níveis de referência nos aspectos mensurados, o que compromete seus resultados (KEENEY, 1992).

Já Pollack-Johnson e Liberatore (2006) utilizam-se de escalas cardinais ancoradas pela percepção do gerente do projeto para a integração dos aspectos relativos a cada uma das etapas do processo construtivo, sendo a integração global (projeto) final realizada por meio de programação linear.

Neste trabalho, com o propósito de dar maior acuracidade ao modelo de apoio à decisão, as escalas ordinais são transformadas em escalas intervalares. A escala de intervalos ocorre quando tem todas as propriedades das escalas ordinais e adicionalmente se conhece a diferença entre todos os níveis. Essa diferença é chamada "diferença de atratividade" entre os níveis. Isto é, se o conhecimento da escala é tão preciso que permite saber a distância entre todos os intervalos da 
escala, então se atinge o grau de mensuração por intervalos, e a escala passa a ser cardinal.

Uma escala intervalar é caracterizada por uma unidade constante e comum de mensuração, que atribui um valor real a todos os pares de objetos no conjunto ordenado. Keeney (1992), Bana e Costa et al. (1999), Ensslin, Dutra e Ensslin (2000), Barzilai (2001) e Ensslin et al. (2010) afirmam que se procura a partir das escalas qualitativas ordinais sua transformação em uma escala de intervalos, por meio da incorporação de informações preferenciais do decisor sobre as diferenças de atratividade entre todos os níveis.

\section{Diagnóstico da situação atual (SQ)}

O diagnóstico da situação compreende a atividade de analisar o desempenho das alternativas e de compor o perfil de desempenho para os critérios estabelecidos pelo decisor.

Em relação a esse quesito, a maior parte dos autores pesquisados, a saber, Kaplinski (2008), Fan, Lin e Sheu (2008), Banaitiene et al. (2008), Cioffi e Khamooshi (2009), Koo et al. (2010), não relata em seus trabalhos como realizar o diagnóstico da situação atual.

Já nos trabalhos de Farris et al. (2006) e PollackJohnson e Liberatore (2006), o diagnóstico da situação atual é realizado localmente em cada um dos aspectos mensurados. Pollack-Johnson e Liberatore (2006) realizam esse diagnóstico pela comparação dos valores obtidos (realizados) com os valores previstos ou metas estipuladas.

Farris et al. (2006) o fazem por meio da comparação com valores de referência, determinados por um projeto benchmarking. A comparação permite a determinação da situação atual de cada aspecto em relação à situação comparada.

Neste trabalho propõe-se que o diagnóstico seja realizado por meio da identificação gráfica da situação atual (status quo) em cada um dos descritores do modelo e também de forma integrada, mensurando o desempenho atual da organização, de forma cardinal local e global.

\section{Formas de aperfeiçoamento}

Entre os artigos selecionados para a análise da literatura, a única proposta de avaliação de desempenho que gera alternativas de aperfeiçoamento é a de Fan, Lin e Sheu (2008). Os autores propõem um modelo matemático que auxilia os gerentes de projeto na definição de ações de resposta a riscos, para mitigá-los em função das características do projeto e da situação do risco. Por meio desse modelo, os gerentes de projeto identificam e analisam alternativas, de forma a escolher a melhor estratégia para mitigar esses riscos. Assim, os gerentes podem escolher estratégias para reduzir os riscos a um nível aceitável, dadas as características do projeto e a situação desses riscos, melhorando o desempenho atual dos projetos.

Nos demais artigos selecionados, a saber, Farris et al. (2006) e Pollack-Johnson e Liberatore (2006), Kaplinski (2008), Banaitiene et al. (2008), Cioffi e Khamooshi (2009), Koo et al. (2010), não foram encontradas formas explícitas de melhoria do desempenho atual.

$\mathrm{Na}$ visão do presente estudo, busca-se o entendimento dos diferentes impactos das ações potenciais nos objetivos julgados necessários e suficientes para a avaliação de um contexto, com o objetivo de explorar oportunidades de melhoria a partir dos descritores construídos para cada um dos critérios adotados.

\section{Metodologia de pesquisa}

\section{Enquadramento metodológico}

A pesquisa é exploratória, aplicada e desenvolvida sob a forma de um estudo de caso. A fonte dos dados é de origem primária, sendo eles obtidos por meio de entrevistas semiestruturadas com os dois principais gestores da organização em que foi realizado o trabalho. O método de pesquisa é qualiquantitativo.

Sobre o instrumento de intervenção adotado, destacam-se, na literatura sobre apoio à decisão, quatro abordagens para resolver problemas (ROY, 1993):

(a) descritivista: caracterizada pelo que acontece no mundo, sem emitir julgamento humano sobre a realidade. São instrumentos advindos das ciências naturais e são adequados onde a relevância da percepção humana é nula;

(b) normativista: caracterizada pela adoção de um modelo que funcionou em outro contexto. Tais modelos são adotados quando os gestores preferem acreditar que instrumentos que foram utilizados em outras organizações são úteis para seu contexto, sem adequações. Assim, a participação do gestor é resumida à escolha do modelo a ser implementado;

(c) prescritivista: caracterizada pela elaboração de modelos de gestão que sejam adequados para dada organização, do ponto de vista de um especialista externo ao contexto. Essa abordagem entende que os processos devem ser personalizados, há um envolvimento da organização para fornecer informações e posteriormente adotam-se as recomendações dadas pelo consultor externo; e

90 Azevedo, R. C.; Ensslin, L.; Lacerda, R. T. de O.; França, L. A.; González, C. J. I.; Jungles, A. E.; Ensslin, S. R. 
(d) construtivista: consiste em desenvolver no gestor, de forma interativa, um coerente corpo de conhecimentos capaz de lhe permitir compreensão das consequências de suas decisões nos aspectos que ele (gestor) julga necessários e suficientes.

Com a adoção da abordagem construtivista, esse trabalho é norteado pelos seguintes paradigmas (LACERDA, ENSSLIN; ENSSLIN, 2011b):

(a) singularidade: os modelos de apoio à decisão devem ser desenvolvidos à luz dos valores e preferências do decisor em dado contexto organizacional. Dessa forma, os modelos são adequados apenas ao contexto em que foram desenvolvidos;

(b) conhecimento: os gestores reconhecem a necessidade de melhorar seu entendimento das consequências da decisão nos seus objetivos estratégicos;

(c) entidade social: os decisores levam em conta, além de seus valores e preferências, a percepção de outros atores, internos e externos à organização;

(d) participação dos decisores: o processo de apoio à decisão é um processo contínuo de envolvimento dos decisores nas atividades cognitivas que lhe farão ter uma aprendizagem por meio de sua participação efetiva;

(e) mensuração: os modelos devem reconhecer as diferentes propriedades e limites de uso das escalas ordinais e cardinais; e

(f) legitimação e validação: todos os produtos de trabalho do processo devem ser reconhecidos pelos gestores como instrumentos que refletem seus valores e preferências a respeito do problema em questão (legitimação). Também devem reconhecer que a abordagem a ser utilizada possui respaldo científico quanto a sua aplicação (validação).

Por reconhecer os paradigmas acima expostos, o instrumento de intervenção adotado para este trabalho foi a Metodologia Multicritério de Apoio à Decisão - Construtivista (MCDA-C).

\section{Revisão da literatura}

O processo de seleção de artigos teve como norte o processo sugerido por Tasca et al. (2010) e teve como base de artigos a Web of Science - ISI, filtrando os trabalhos publicados a partir de 2006 e ordenando-os pelo número de citações.

Por meio da análise de título e resumos, selecionaram-se os artigos que estavam mais alinhados com o objeto de pesquisa (FARRIS et al., 2006; POLLACK-JOHNSON; LIBERATORE, 2006; BANAITIENE et al., 2008; FAN; LIN; SHEU, 2008; KAPLINSKI, 2008; CIOFFI; KHAMOOSHI, 2009; KOO et al., 2010).

\section{Construção do modelo multicritério: procedimentos}

A construção do modelo de avaliação de desempenho segundo a metodologia MCDA-C é dividida em três fases como apresentado na Figura 1 (BANA E COSTA et al., 1999; ENSSLIN et al., 2010):
(a) estruturação;
(b) avaliação, e
(c) recomendações.

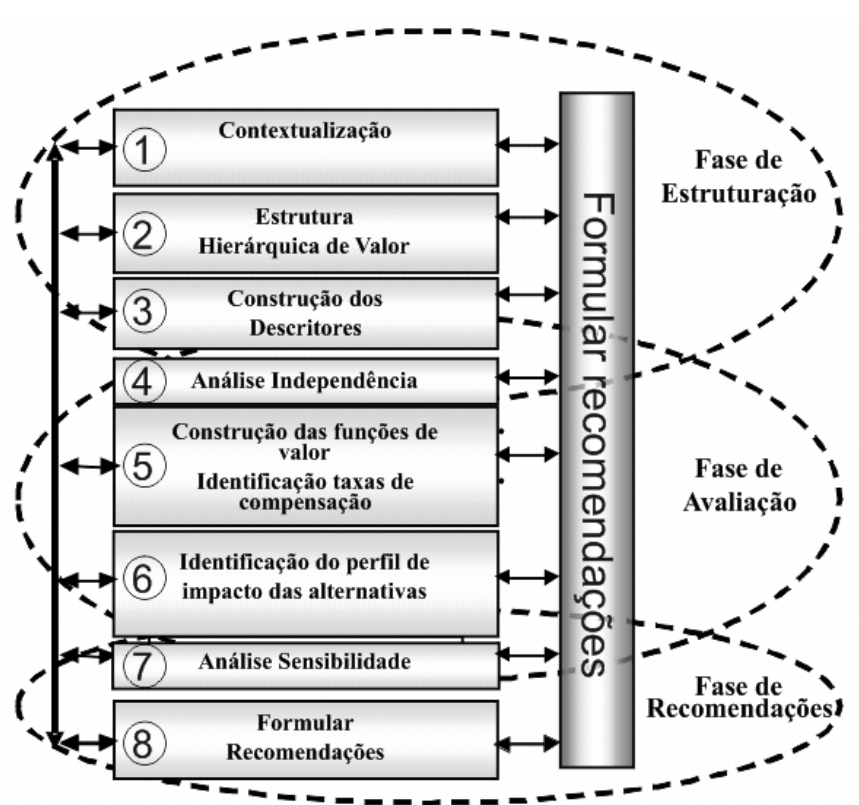

Figura 1- As fases da metodologia MCDA-C

Fonte: Adaptado de Ensslin et al. (2001). 


\begin{tabular}{|l|l|l|}
\hline \multirow{4}{*}{ Stakeholders } & Decisor & Gerente de Engenharia \\
\cline { 2 - 3 } & \multirow{4}{*}{ Intervenientes } & $\begin{array}{l}\text { Empresa de } \\
\text { orçamentação executiva }\end{array}$ \\
& & Engenheiros de obra \\
& & Analista da qualidade \\
\cline { 2 - 2 } & & GestCon/UFSC \\
\cline { 2 - 3 } & Facilitadores & Autores \\
\hline \multirow{2}{*}{ Agidos } & Quadro funcional \\
\cline { 2 - 2 } & Terceirizados \\
\cline { 2 - 2 } & Clientes da empresa \\
\hline
\end{tabular}

Quadro 1 - Subsistema de Atores

\section{Modelo multicritério para avaliação de orçamentação em construção civil}

As informações relativas ao contexto avaliado foram obtidas em reuniões realizadas conforme um cronograma de atividades previamente proposto, envolvendo nove reuniões de levantamento e validação, com carga horária total estimada em 40 horas de envolvimento dos decisores e de 200 horas para os facilitadores.

A cada reunião era apresentado um resumo da reunião anterior e do trabalho desenvolvido sobre as informações levantadas, para validação e maior detalhamento, quando necessário. Todas as informações levantadas e os resultados das validações foram registrados em atas, utilizadas como base para as etapas de desenvolvimento posteriores.

\section{Estruturação do modelo}

A seguir, estão as seções que explicitam as atividades da Fase de Estruturação da MCDA-C.

\section{Contextualização}

A empresa pesquisada certificou-se em julho de 2007 em duas das principais normas de qualidade existentes para o setor: a NBR ISO 9001:2000 Sistemas de Gestão da Qualidade; e o SIACPBQP-H, Nível A - Programa Brasileiro de Qualidade e Produtividade no Habitat.

Como passo inicial para a estruturação desse modelo, buscou-se identificar para quem seria realizado o apoio à decisão, ou seja, quem dentro do quadro da empresa seria o ator com o poder de alterar a situação atual (decisor), quais seriam os atores com poder de interferência nesse processo (intervenientes) e quais seriam influenciados pelas decisões a serem tomadas (agidos). Esses atores são mostrados no Quadro 1.

Dentro da contextualização, a primeira preocupação foi definir um rótulo que representasse as principais preocupações fundamentais do decisor quanto ao problema. Esse rótulo foi definido como: construir um modelo para apoiar a orçamentação de obras de construção civil em uma construtora de SC.

\section{Estrutura hierárquica de valor}

Durante as entrevistas realizadas, solicitou-se ao decisor que discorresse livremente sobre o problema a ser avaliado. As informações coletadas foram analisadas para identificação dos Elementos Primários de Avaliação (EPAs). Os EPAs são o registro das principais propriedades do contexto avaliado que o decisor julga relevantes em função do objetivo pretendido. A análise das primeiras entrevistas permitiu a identificação de 114 EPAs. Os dez primeiros EPAs identificados são exibidos no Quadro 2.

O próximo passo da Metodologia MCDA-C é a construção de conceitos a partir dos EPAs. Os conceitos representam a expansão do entendimento dos EPAs. Cada um deve estabelecer a direção de preferência do decisor (chamado polo presente) e, também, estabelecer a consequência que se deseja evitar ou minimizar (polo oposto psicológico)

Os dez conceitos construídos a partir dos primeiros EPAs são exibidos no Quadro 3, em que as reticências (“...”) devem ser lidas como "ao invés de".

Como os EPAs foram identificados em um processo de brainstorming, é comum o surgimento de conceitos redundantes que devem ser unificados, como os conceitos C2 e C9. 


\begin{tabular}{|c|l|}
\hline EPA & \multicolumn{1}{|c|}{ Descrição } \\
\hline 1 & Definir material para acabamento \\
\hline 2 & Classificar material para acabamento \\
\hline 3 & Definir fornecedores para material de acabamento \\
\hline 4 & Definir similares para material de acabamento \\
\hline 5 & Levantar os preços de material de acabemento \\
\hline 6 & Usar os materiais de acabamento definidos \\
\hline 7 & Memorial descritivo \\
\hline 8 & Check list para memorial descritivo \\
\hline 9 & Definir padrões para materiais \\
\hline 10 & Ter projeto de áreas comuns \\
\hline
\end{tabular}

Quadro 2 - Relação dos 10 primeiros EPAs identificados

\begin{tabular}{|c|l|}
\hline Conceito & \multicolumn{1}{|c|}{ Descrição } \\
\hline C1 & $\begin{array}{l}\text { Ter materiais predefinidos de acabamento ... ter dificuldades na seleção de materiais para } \\
\text { acabamento }\end{array}$ \\
\hline C2 & $\begin{array}{l}\text { Ter categoriaspreestabelicidas com seus materiais de acabamento (linha de produto/fornecedor) } \\
\text {.. cada empreendimetno ter materiais sem padronização }\end{array}$ \\
\hline C3 & $\begin{array}{l}\text { Selecionar fornecedores de referência para os materiais de acabamento ... ter dificuldade na } \\
\text { cotação do material }\end{array}$ \\
\hline C4 & $\begin{array}{l}\text { Definir similaridades entre os materiais de acabamento ... não poder substituir material } \\
\text { (produto) }\end{array}$ \\
\hline C5 & $\begin{array}{l}\text { Ter as cotações de todos os materiais de acabamento/produto ... estimar custos sem informações } \\
\text { reais }\end{array}$ \\
\hline C6 & $\begin{array}{l}\text { Garantir que os materiais definidos sejam utilizados na execução ... ter mudanças não } \\
\text { autorizadas/analisadas }\end{array}$ \\
\hline C7 & $\begin{array}{l}\text { Ter um memorial descritivo com todos os itens definidos no modelo de memorial descritivo ... } \\
\text { ter um memorial ambíguo/incompleto }\end{array}$ \\
\hline C8 & $\begin{array}{l}\text { Garantir a padronização da eleboração dos memoriais descritivos ... ter variações na elaboração } \\
\text { de um memorial descritivo }\end{array}$ \\
\hline C9 & Vide conceito 2 \\
\hline C10 & $\begin{array}{l}\text { Garantir que projetos de áreas comuns sejam incluidos no orçamento ... áreas comuns serem } \\
\text { executadas com parte do lucro previsto }\end{array}$ \\
\hline
\end{tabular}

\section{Quadro 3 - Os dez conceitos construídos a partir dos EPAs}

Após essa atividade, gerou-se um entendimento maior do contexto estudado. A partir desse entendimento global, os facilitadores, em conjunto com o decisor, partiram para a identificação de objetivos estratégicos associados ao conhecimento até então construído.

Assim, com a leitura de todos os conceitos, o decisor, apoiado pelo facilitador, refletiu sobre o contexto holisticamente, a fim de identificar os objetivos mais estratégicos, organizando-os em uma estrutura hierárquica.

Uma vez estabelecidos os objetivos estratégicos associados ao contexto, faz-se necessário testar os objetivos no tocante às propriedades de necessidade e suficiência diante dos conceitos anteriormente levantados.

Para atender a essas duas propriedades, o decisor, novamente apoiado pelo facilitador, relacionou cada conceito a um objetivo (necessidade), e nenhum conceito ficou sem objetivo estratégico relacionado (suficiência).

A Figura 2 apresenta os objetivos estratégicos deste estudo, bem como lista todos os conceitos a eles relacionados.

\section{Construção dos descritores}

A construção dos mapas de relação meios-fim iniciou-se solicitando ao decisor discorrer sobre cada conceito e sobre como ele poderia ser obtido (vínculos causais com outros conceitos), favorecendo a identificação das possíveis ações aptas a gerar efeitos no desempenho dos objetivos subjacentes (EDEN; JONES; SIMMS, 1985; MONTIBELLER et al., 2008). 


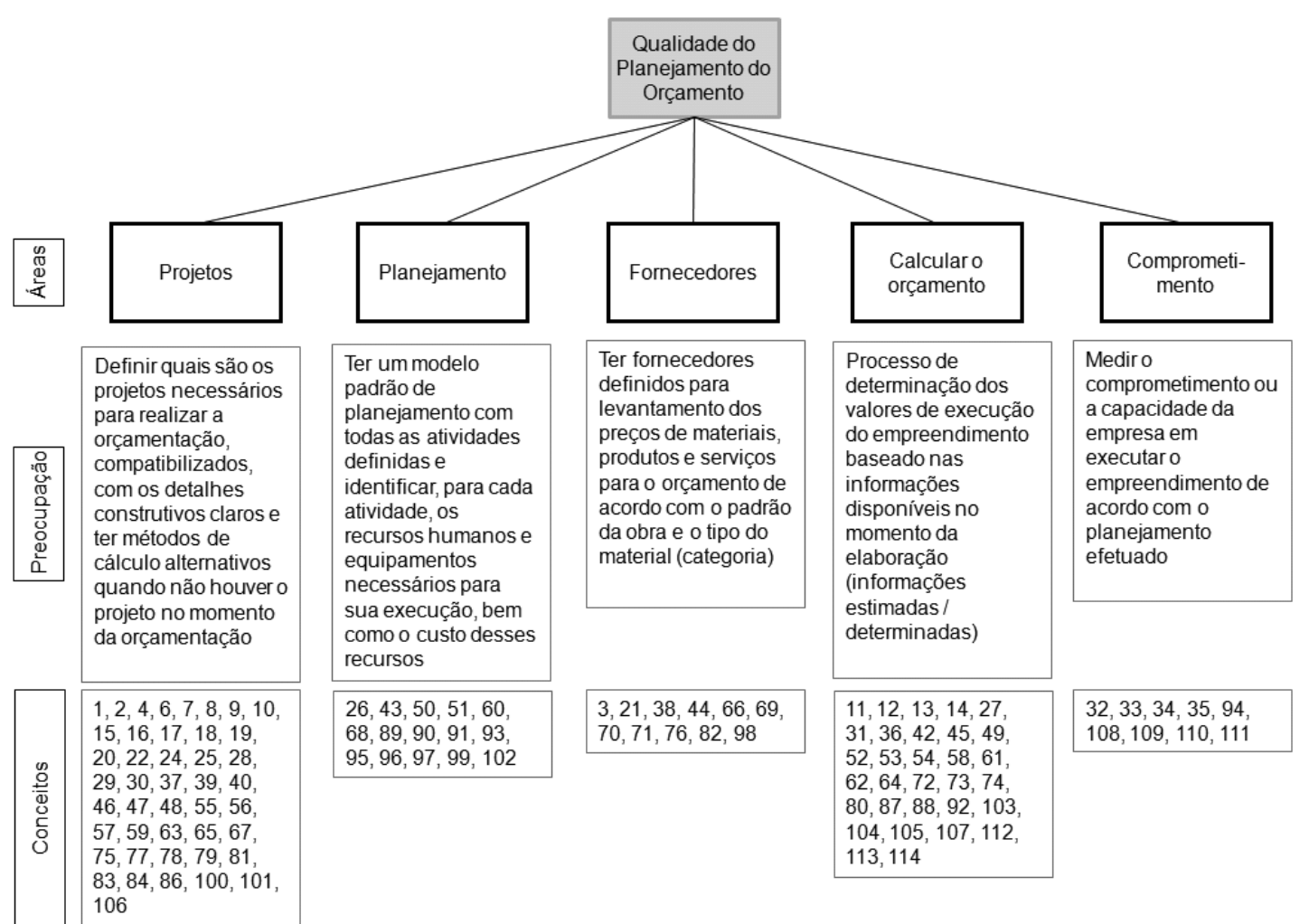

Figura 2 - Estrutura top-down do modelo de avaliação e os conceitos a eles relacionados

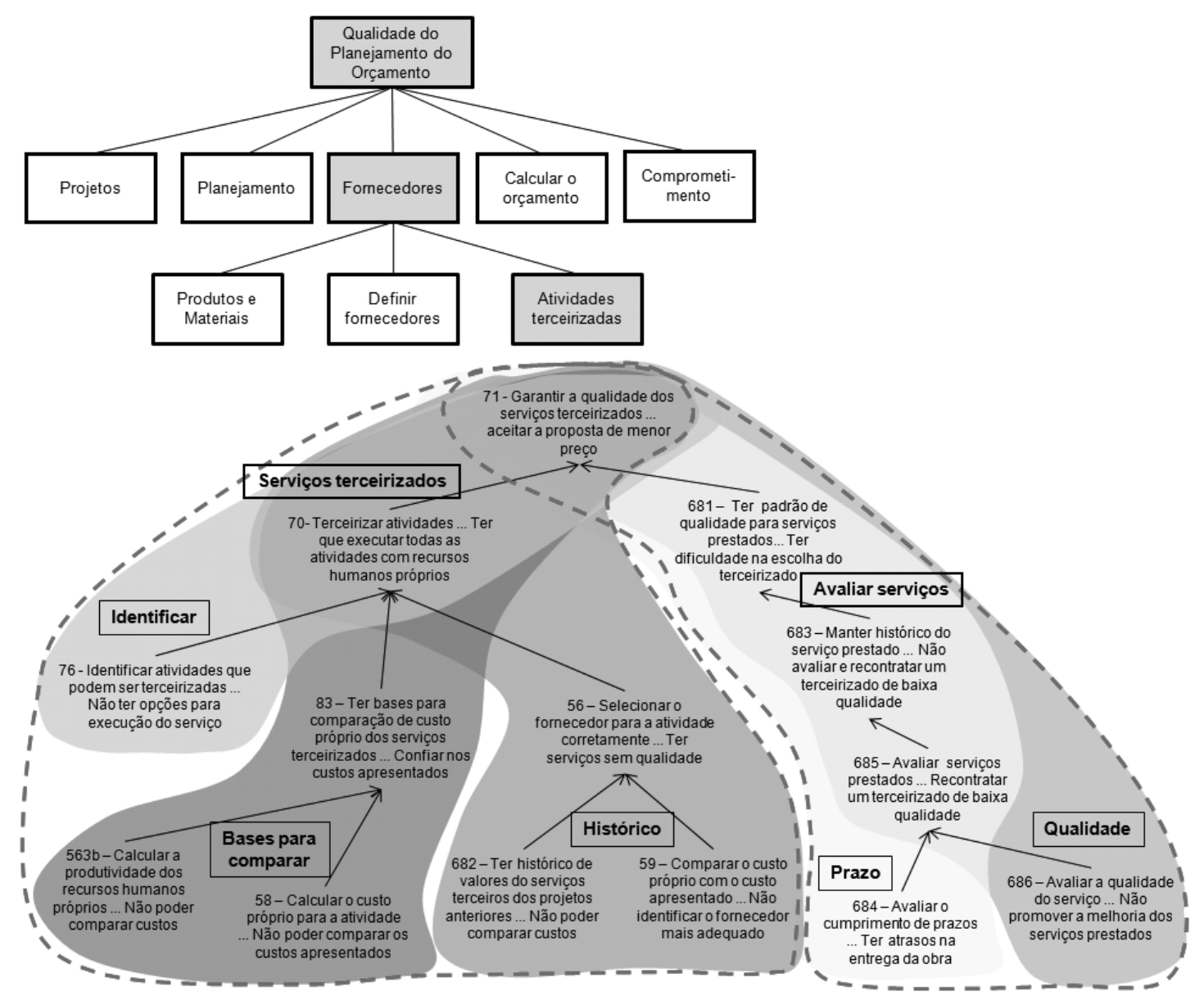

Figura 3 - Mapas de relações meios-fim para o objetivo estratégico "Atividades Terceirizadas"

94 Azevedo, R. C.; Ensslin, L.; Lacerda, R. T. de O.; França, L. A.; González, C. J. I.; Jungles, A. E.; Ensslin, S. R. 
Com essa atividade, é possível identificar linhas de argumentação que conduzem os conceitos-meios aos conceitos mais estratégicos. A associação das linhas de argumentação a uma preocupação do decisor é chamada de cluster.

A Figura 3 exibe o mapa de relação meios-fim para o objetivo estratégico "Atividades Terceirizadas" com seus clusters e subclusters nomeados. Os conceitos com numeração acima de 500 surgiram durante a construção dos mapas.

Finalizada a construção dos mapas de relação meios-fim para todos os objetivos estratégicos da estrutura hierárquica top-down, a metodologia MCDA-C, em seu processo de construção de conhecimento sobre o contexto avaliado, propõe que as estruturas de relações causais sejam transformadas e transportadas para a estrutura arborescente elaborada anteriormente.

Essa estrutura é chamada de Estrutura Hierárquica de Valor, em que se identificam os pontos de vista fundamentais (PVFs) e os pontos de vista elementares (PVEs). Para que isso seja feito, cada cluster deve ser testado para validar se representa o contexto de forma a ser essencial, controlável, completo, mensurável, operacional, isolável, não redundante, conciso e compreensível (KEENEY, 1992; ENSSLIN; MONTIBELLER; NORONHA, 2001).

A Figura 4 ilustra a Estrutura Hierárquica de Valor, detalhando os pontos de vista fundamentais (PVFs) e os pontos de vista elementares (PVEs) do PVF 7 - "Atividades Terceirizadas". A partir de cada elemento no nível inferior da Estrutura Hierárquica de Valor inicia-se a construção dos descritores.

Os descritores (escalas ordinais) possuem uma escala de medida que associa os valores abstratos do decisor a uma ou mais propriedades do objeto, sendo a ordem de preferência dos possíveis desempenhos dela estabelecida pelo decisor. Essa associação é usualmente muito complexa, necessitando do uso de instrumentos científicos para sua realização (KEENEY; RAIFFA, 1976; KEENEY, 1992).

A metodologia MCDA-C realiza essa associação por meio de mapas cognitivos. Os valores abstratos do decisor aparecem no mapa cognitivo como os conceitos-fins (parte superior do mapa); sua operacionalização ocorre pelos caminhos que levam aos conceitos-meios.

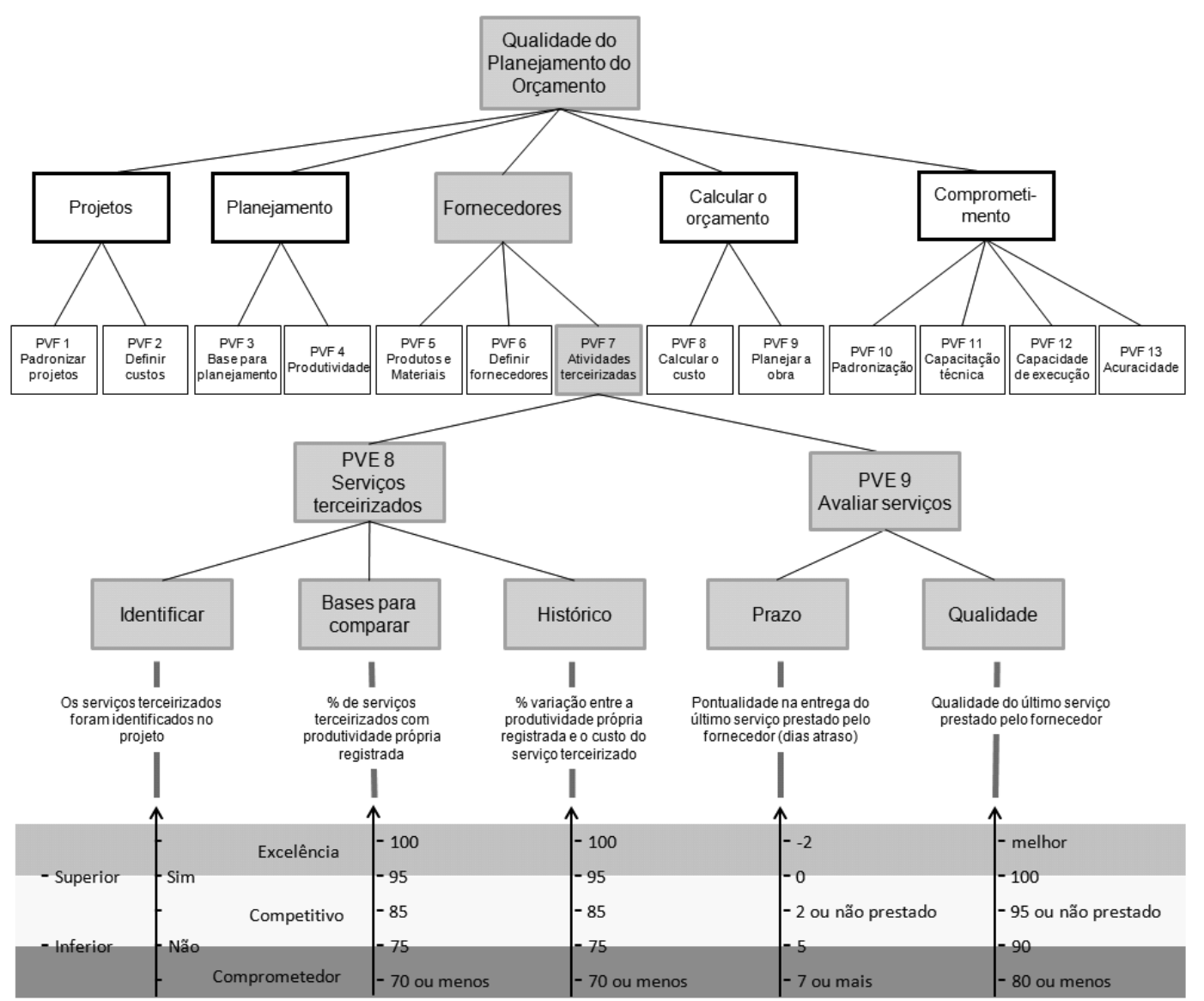

Figura 4 - Estrutura hierárquica de valor do PVF 7, atividades terceirizadas, com seus PVEs e descritores 
Sobre o conhecimento gerado é construído o descritor, que poderá ser qualitativo, gráfico, pictórico ou representado por símbolos alfanuméricos (BANA E COSTA et al., 1999; DUTRA et al., 2009; ENSSLIN et al., 2010).

Para essa atividade, utilizam-se primeiramente escalas ordinais, construídas em conjunto com o decisor, representando o que ele considera relevante ser mensurado no critério abordado. É importante destacar que todos os conceitos de um cluster devem ser levados em conta quando da construção de um descritor, em vez de mensurar somente o conceito mais operacional.

Além da escala ordinal, o decisor identificou os níveis de referência: superior, representando o nível acima do qual o desempenho é considerado excelente; e inferior, representando o nível abaixo do qual o desempenho é considerado comprometedor. Entre esses dois níveis, o desempenho é considerado normal.

A Figura 4 também ilustra os descritores relacionados aos PVEs da Estrutura Hierárquica de Valor para o PVF 7, Atividades Terceirizadas. Ao todo, o modelo multicritério construído é composto de 51 descritores.

Finalizada a construção da Estrutura Hierárquica de Valor e dos descritores, encerra-se a fase de estruturação do modelo e parte-se para a fase de Avaliação.

\section{Avaliação}

Seguem as subseções da etapa de avaliação, que visa integrar o modelo em escalas cardinais.

\section{Análise de independência}

A MCDA-C pressupõe que as taxas de compensação utilizadas na integração são constantes. Para atingir essa condição, os critérios devem ser independentes (LACERDA; ENSSLIN; ENSSLIN, 2011b).

Assim, todos os descritores foram testados conforme a Independência Preferencial Mútua exposta por Keeney (1992) e foram constatados como mútua e preferencialmente independentes, tanto ordinal como cardinalmente.

\section{Construção de funções de valores e identificação das taxas de compensação}

Nas seções seguintes estão contidos os procedimentos adotados neste trabalho para as funções de valores e taxas de compensação.

\section{Funções de valor}

Neste estudo de caso, escolheu-se o método Macbeth para criar as funções de valor, dando fundamentação teórica, reconhecimento científico e praticidade ao processo.

O Macbeth permite avaliar opções comparando-as qualitativamente em termos de suas diferenças de atratividade em múltiplos critérios (BANA E COSTA; VANSNICK, 1995).

A partir das respostas do decisor sobre a intensidade da diferença de atratividade entre os níveis da escala ordinal, construiu-se a Matriz de Julgamentos, cujos valores são utilizados como entrada para o software M-Macbeth na determinação da função de valor que irá transformar a escala ordinal em uma escala cardinal.

A Figura 5 ilustra a transformação da escala ordinal em escala cardinal, onde são exibidos a Estrutura Hierárquica de Valor, o Descritor D27 Prazo, a Matriz de Julgamento Macbeth, a função de valor (escala cardinal) numérica "V(a)" e a função gráfica correspondente.

A Figura 6 exibe o conjunto de escalas cardinais "V(a)", construídas para o PVF 7, Atividades Terceirizadas, bem como as escalas ordinais "a" originais.

A construção das funções de valor relativas aos descritores viabiliza a mensuração cardinal de cada um dos aspectos (critérios) considerados relevantes pelo decisor.

Contudo, para a integração desses critérios, ainda se faz necessário identificar a contribuição de cada critério para o desempenho global do orçamento, surgindo a necessidade de taxas de compensação.

\section{Taxas de compensação}

O método utilizado para a determinação das taxas de compensação foi a Comparação Par a Par com o software Macbeth.

Como ilustração, deseja-se determinar as taxas de compensação para os critérios D24 - "Identificar", D25 - "Bases para comparar" e D26 - "Histórico", que permitirão a mensuração do PV 8 - "Serviços Terceirizados" (vide Figura 6).

Segundo Keeney (1992), o erro crítico mais comum em modelos multicritérios é estabelecer taxas de compensação sem estabelecer os níveis de referência nos critérios aos quais as taxas estão relacionadas. Mudam-se os níveis de referência, mudam-se as taxas de compensação. 

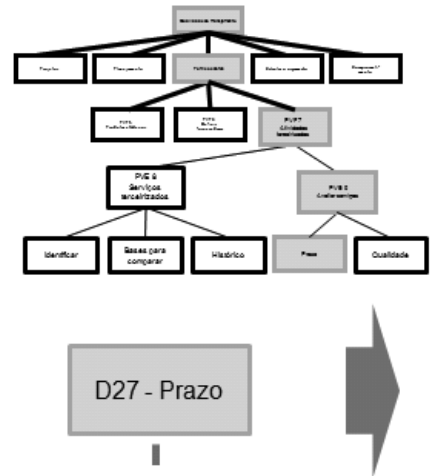

Pontualidade na entrega do último serviço prestado pelo fornecedor (dias atraso)

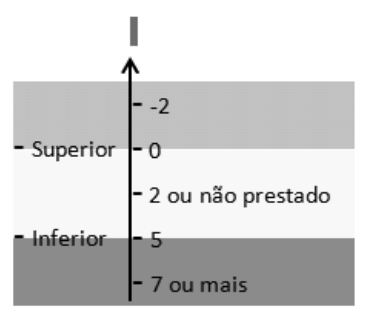

\section{Transformação escala ordinal em cardinal}

Matriz de Julgamentos Macbeth
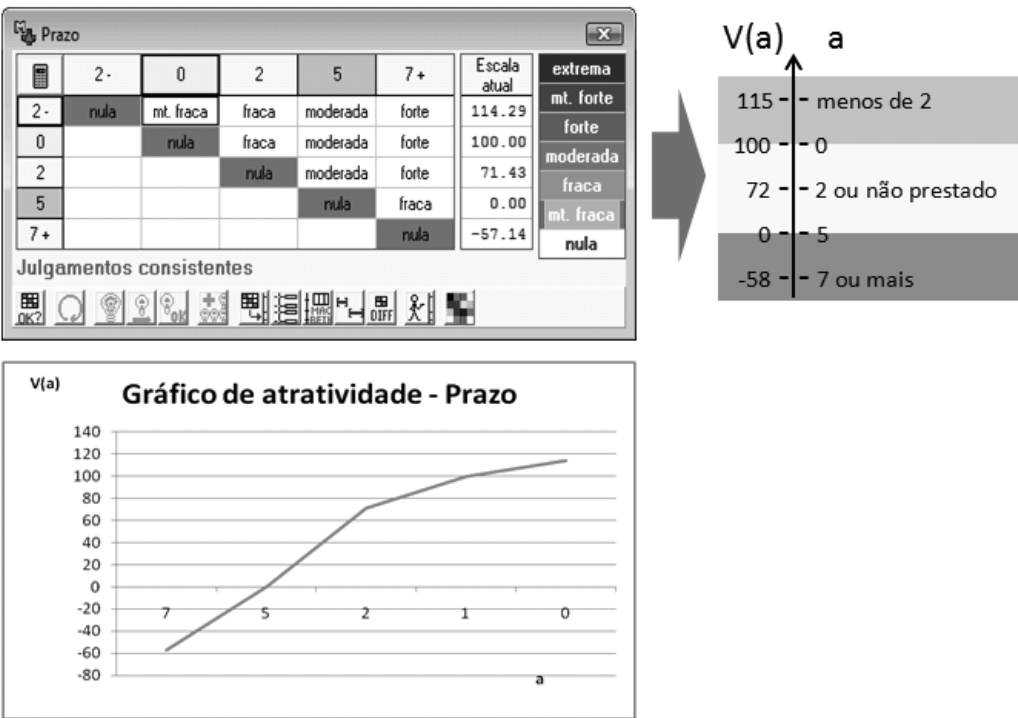

Figura 5 - Transformação do descritor D27 prazo em função de valor por meio do método Macbeth

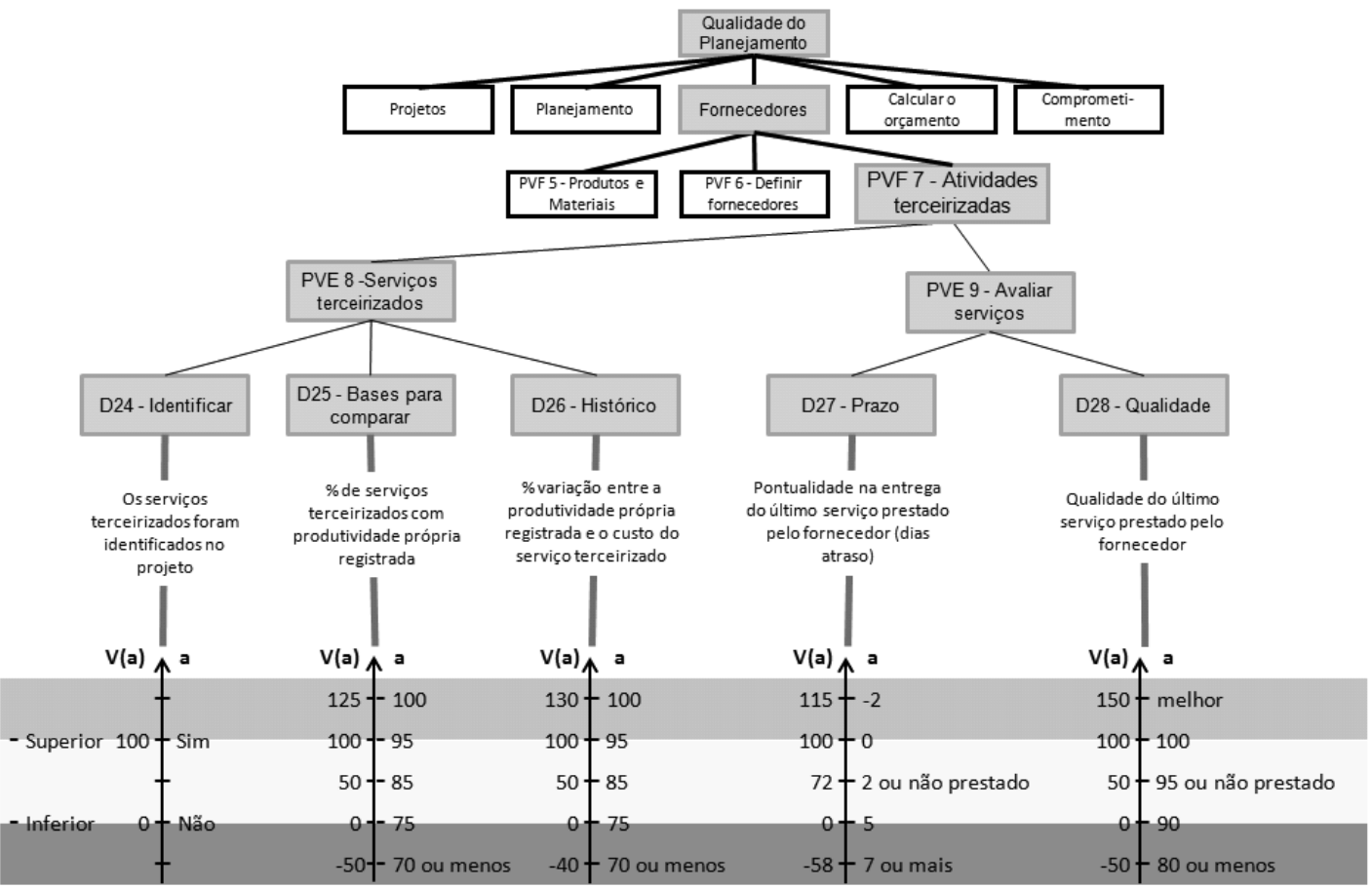

Figura 6 - Escalas cardinais do PVF 7, atividades terceirizadas

Para que o decisor possa expressar seus julgamentos de valor, que permitirão a determinação das taxas de compensação, é necessário criar alternativas que representem a passagem do nível inferior para o nível superior em cada um dos critérios, bem como uma alternativa com desempenho inferior em todos os critérios abrangidos, conforme mostrado na Figura 7.

Em seguida, as alternativas devem ser ordenadas segundo o juízo preferencial do decisor. Uma vez que as alternativas sejam ordenadas, tem-se uma escala ordinal em que se utilizou do mesmo instrumento para a identificação das funções de valores descritos na subseção anterior. 


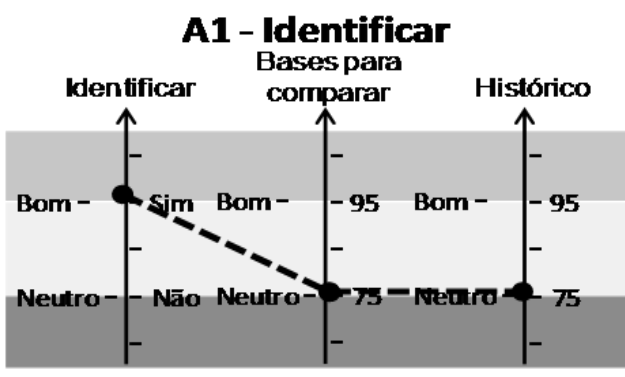

A3 - Histórico

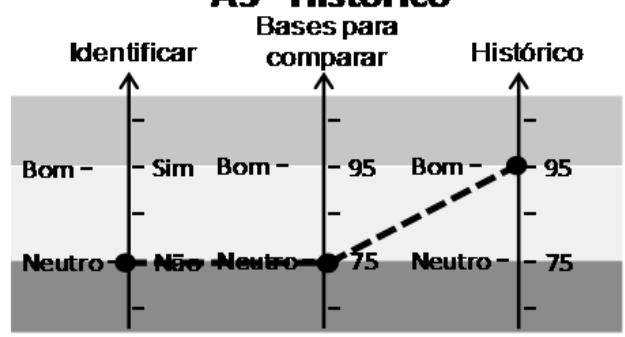

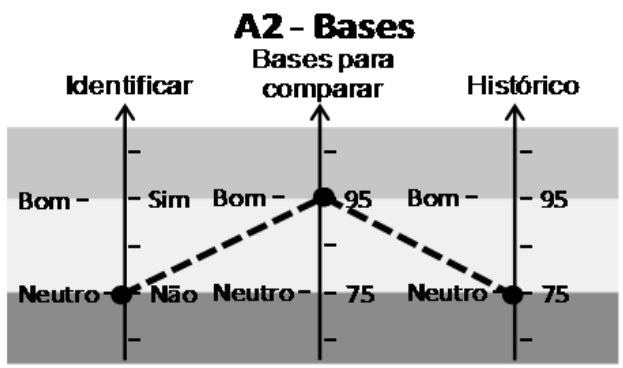

AO

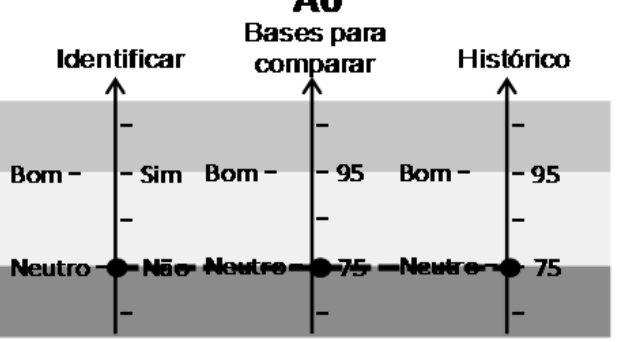

Figura 7 - Alternativas potenciais para a determinação das taxas de compensação

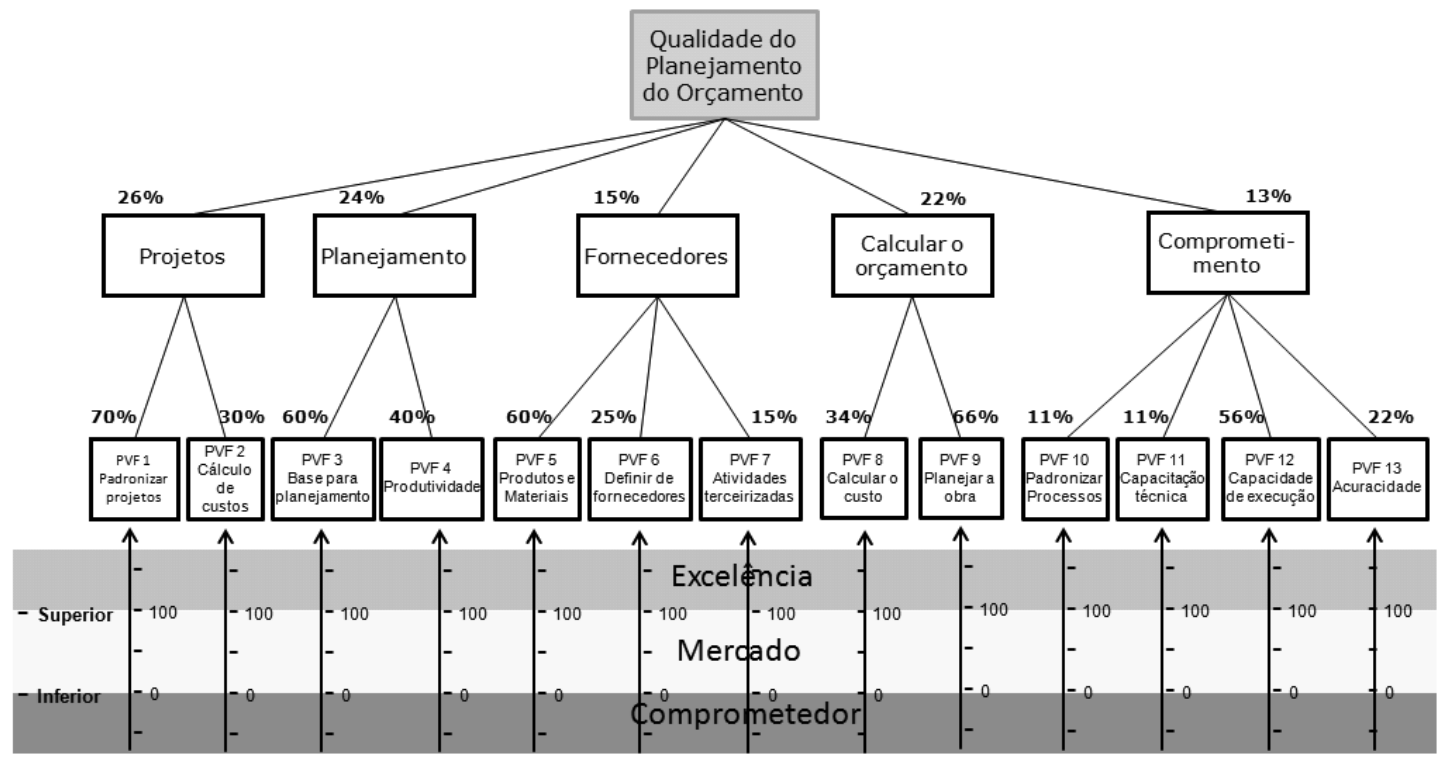

Figura 8 - Estrutura Hierárquica de Valor Global com Taxas de Compensação

Dessa forma, foi possível determinar as taxas de compensação de cada um dos PVFs e PVEs, conforme mostrado na Figura 8 , e dar início à dedução da equação do valor global do modelo multicritério.

\section{Função de valor global do modelo}

Com o conhecimento gerado até o momento, podese presumir a equação para determinação do valor de qualquer ponto de vista do modelo. Retomando o exemplo do item anterior, a Equação 1 do PV 8 "Serviços Terceirizados" é dada por:

$\mathrm{V}_{\mathrm{PV} 8(\mathrm{a})}=0,24 \mathrm{x} \mathrm{V}_{\mathrm{D} 24 \text { (a) }}+0,43+\mathrm{V}_{\mathrm{D} 25 \text { (a) }}+0,33 \mathrm{x}$ $\mathrm{V}_{\mathrm{D} 26 \text { (a) }}$
Onde as constantes são as taxas de compensação relativas aos descritores determinadas no item anterior (vide Figura 8).

Dessa forma, a equação genérica para cada Ponto de Vista Fundamental terá a forma da Equação 2:

$$
V_{P V F k}(a)=\sum_{i=1}^{n_{k}} W_{i, k} \times V_{i, k}(a)
$$

Onde:

$V_{P V F K}(\mathrm{a})$ : valor global da ação a do PVFk, para $\mathrm{k}=$ $1,2, \ldots, \mathrm{m}$;

$W_{i, k}$ : taxa de substituição do critério $i, i=1, \ldots, n$, do $\mathrm{PVF}_{\mathrm{k}}$, para $k=1,2, \ldots, m$; 
$V_{i, k}(\mathrm{a})$ : valor parcial da ação a do critério $i, i=1$, $\ldots n$, do $\mathrm{PVF}_{\mathrm{k}}$, para $k=1, \ldots, m$;

$a$ : nível de desempenho atingido no critério com a ação $a$;

$n_{k}$ : número de critérios do $\mathrm{PVF}_{\mathrm{k}}$, para $k=1,2, \ldots$, $m ; \mathrm{e}$

$m$ : número de PVF's do modelo global.

Para ilustrar, a equação para o PVF 7 “Atividades Terceirizadas" é dada pela Equação 3, onde as constantes utilizadas são as próprias taxas de compensação de cada ponto de vista.

$\mathrm{V}_{\text {Ativ. Terceirizadas }}=0,25 \times\left\{0,24 \times \mathrm{V}_{\text {Identificador }}+0,43 \times\right.$

$\left.\mathrm{V}_{\text {Bases para comparar }}+0,33 \times \mathrm{V}_{\text {Histórico }}\right\}+0,75 \times\{0,50 \times$

$\left.\mathrm{V}_{\text {Prazo }}+0,50 \times \mathrm{V}_{\text {Qualidade }}\right\} \quad$ Eq. 3

A partir desse momento o modelo está pronto para ser utilizado como apoio ao processo de gestão de orçamentos dos empreendimentos da empresa.

\section{Identificação do perfil de impacto das alternativas}

\section{Determinação do status quo}

A Figura 9 ilustra a determinação do Status Quo do PVF “Atividades Terceirizadas". Para cada critério de avaliação (descritor) do ponto de vista, buscou-se objetivamente o desempenho alcançado (a) pela empresa na construção do orçamento do empreendimento A. Por meio da função de valor obteve-se a pontuação $V(a)$ correspondente na escala cardinal. A utilização da Equação 3 resulta na pontuação do PVF 7 (43 pontos).

A determinação do status quo de um processo de orçamento recente permitiu identificar os pontos fortes e fracos da empresa em relação ao problema analisado e forneceu os subsídios necessários para o apoio ao processo. Dos 51 descritores que compõem o modelo global, 37 deles possuíam desempenho comprometedor.

Da mesma forma, dos 13 objetivos estratégicos destacados na Figura 8, apenas quatro possuíam desempenho competitivo (PVF 6 - Definir Fornecedores, PVF 7 - Atividades Terceirizadas, PVF 10 - Padronização e PVF 11 - Capacitação Técnica).

O modelo de avaliação, construído de acordo com as preferências e valores do decisor, permitiu identificar a contribuição de cada um dos aspectos considerados relevantes para o contexto estudado.

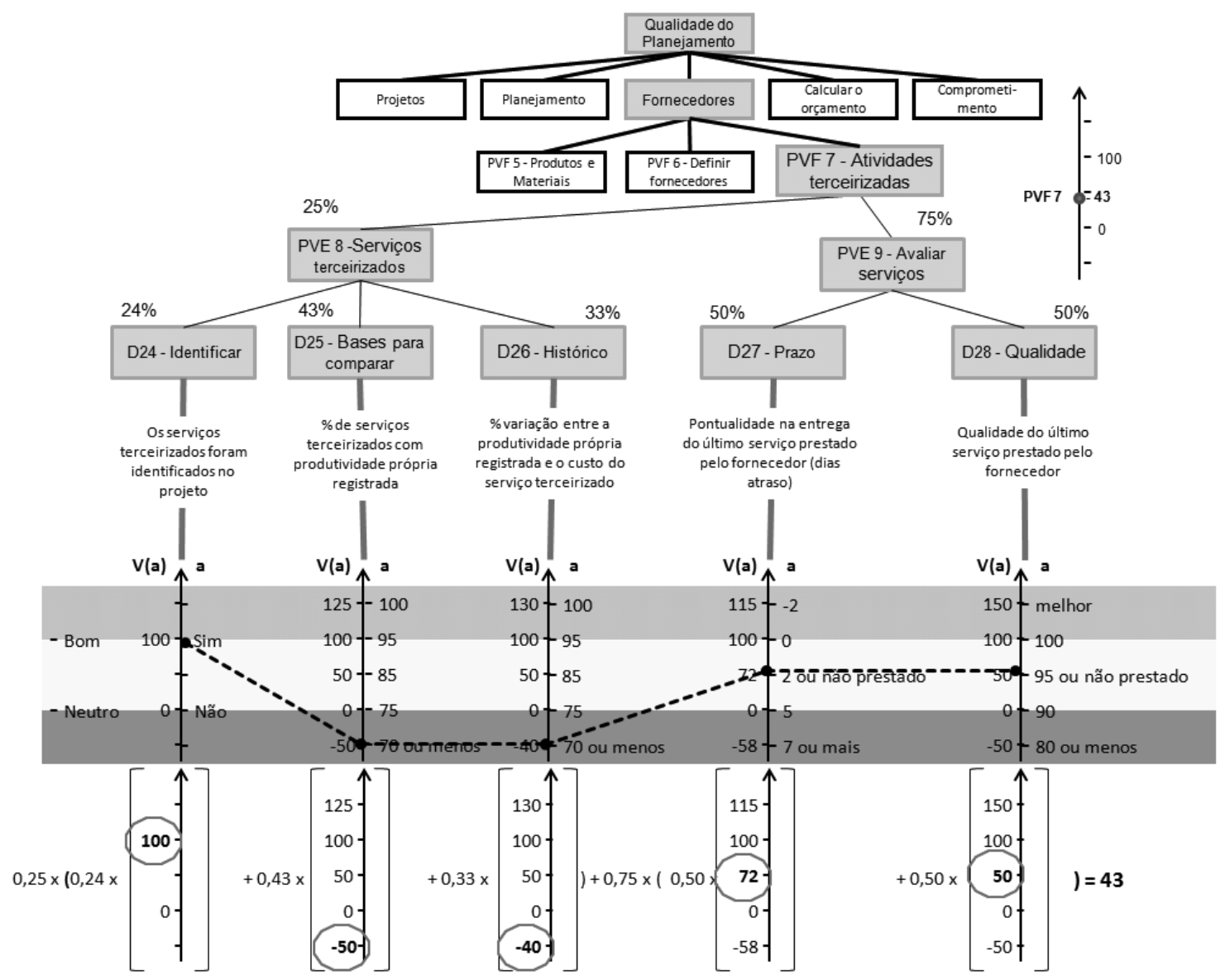

Figura 9 - Determinação do status quo do PVF Atividades Terceirizadas 


\section{Recomendações}

Assim, partindo do status quo determinado pelo modelo de avaliação global, o decisor identificou os PVFs com pior desempenho e, baseado nestes, elencou três focos para o desenvolvimento de Planos de Ações destinados a melhorar a performance da empresa no processo de orçar um empreendimento.

Esses focos foram:

(a) fornecedores: melhoria da qualidade do relacionamento com os fornecedores por meio da melhoria da qualidade de prestação de serviços, preços e fornecimento de materiais;

(b) padronização: melhoria da qualidade dos processos internos da empresa; e

(c) produtividade: melhoria dos cálculos de custos de projetos e serviços a partir das informações de produtividade da empresa.

Para cada um dos planos foram identificados os critérios que seriam afetados pelos mesmos. A análise desses critérios (descritores), que por sua própria construção permitem distinguir o desempenho melhor do pior, constituiu a base para a identificação das ações necessárias para que os objetivos estratégicos fossem atingidos.

Em seguida, com base na ação de melhoria identificada, o decisor determinou a meta que deveria ser atingida (nível de desempenho) para cada critério afetado por essa ação.

Para efeito de comparação do custo/benefício, o decisor estimou o custo financeiro de cada um dos planos com base unicamente no custo dos recursos humanos que seriam necessários para sua implementação e na manutenção durante um período.

Por sugestão dos facilitadores, montou-se um quarto plano de ações (Plano Geral), englobando as ações distintas de cada um dos planos anteriores. O Quadro 4 exibe as informações gerais dos Planos de Ação, com o resultado obtido, o custo financeiro e o respectivo custo por ponto obtido.

\section{Formulação das recomendações}

Para a metodologia MCDA-C, a etapa de Recomendações tem como objetivo auxiliar o decisor a identificar as melhores formas para alavancar o desempenho em relação ao contexto que está sob avaliação, assim como compreender as consequências dessas ações em seus objetivos estratégicos caso estas venham a ser implementadas.

Em alguns casos pode ser necessário analisar em que medida o desempenho das alternativas se altera em função da modificação da taxa de substituição do PVF ou PVE analisado. Esse procedimento é denominado Análise de Sensibilidade.

A análise de sensibilidade realizada no modelo proposto demonstrou que a alternativa "Padronização" é robusta a eventuais variações na taxa de substituição do PVF "Atividades Terceirizadas". Também evidenciou a predominância do Plano de Ações cujas ações envolviam um maior número de descritores do PVF analisado.

Cabe ressaltar que não é função da etapa de Recomendações ditar ações, mas sim servir de apoio para ajudar o decisor a construir ações e a avaliar suas consequências.

A Figura 10 exibe um exemplo de como a formulação de recomendações é realizada. O decisor, juntamente com os atores envolvidos, estabeleceu as alternativas necessárias para fazer com que o desempenho do descritor melhore. Como pode ser observado, a ação proposta foi decomposta nos passos necessários para sua implementação. Isso permitirá elevar a performance do PVE, levando-o de um desempenho comprometedor (30\% de variação) para um desempenho de excelência $(5 \%$ de variação).

\begin{tabular}{|l|l|c|c|c|c|c|}
\hline \multicolumn{1}{|c|}{ Plano } & \multicolumn{1}{|c|}{ Descrição } & $\begin{array}{c}\text { Status } \\
\text { Quo }\end{array}$ & Resultado & $\begin{array}{c}\text { Pontos } \\
\text { Obtidos }\end{array}$ & $\begin{array}{c}\text { Custo } \\
\text { Fornecedores }\end{array}$ & $\begin{array}{c}\text { Custo por } \\
\text { ponto }\end{array}$ \\
\hline Produtividade & $\begin{array}{l}\text { Melhorar a qualidade do relacionametno com os } \\
\text { fornecedores por meio da melhoriada qualidade } \\
\text { de materiais e produtos }\end{array}$ & -36 & -17 & 19 & 30.000 & 1.579 \\
& $\begin{array}{l}\text { Melhoria dos cálculos de custosde projetos e } \\
\text { serviços a partir das informações de } \\
\text { produtividade da empresa }\end{array}$ & -36 & 18 & 54 & 56.000 & 1.037 \\
\hline Padronização & $\begin{array}{l}\text { Melhoria da qualidade dos processos internos da } \\
\text { empresa }\end{array}$ & -36 & 38 & 74 & 103.000 & 1.392 \\
\hline Geral & $\begin{array}{l}\text { Resultado global de todas as ações dos planos de } \\
\text { Fornecedores, Padronização e Produtividade }\end{array}$ & -36 & 95 & 131 & 132.000 & 1.008 \\
\hline
\end{tabular}

Quadro 4 - Planos de ações propostos com seus custos e pontos obtidos 


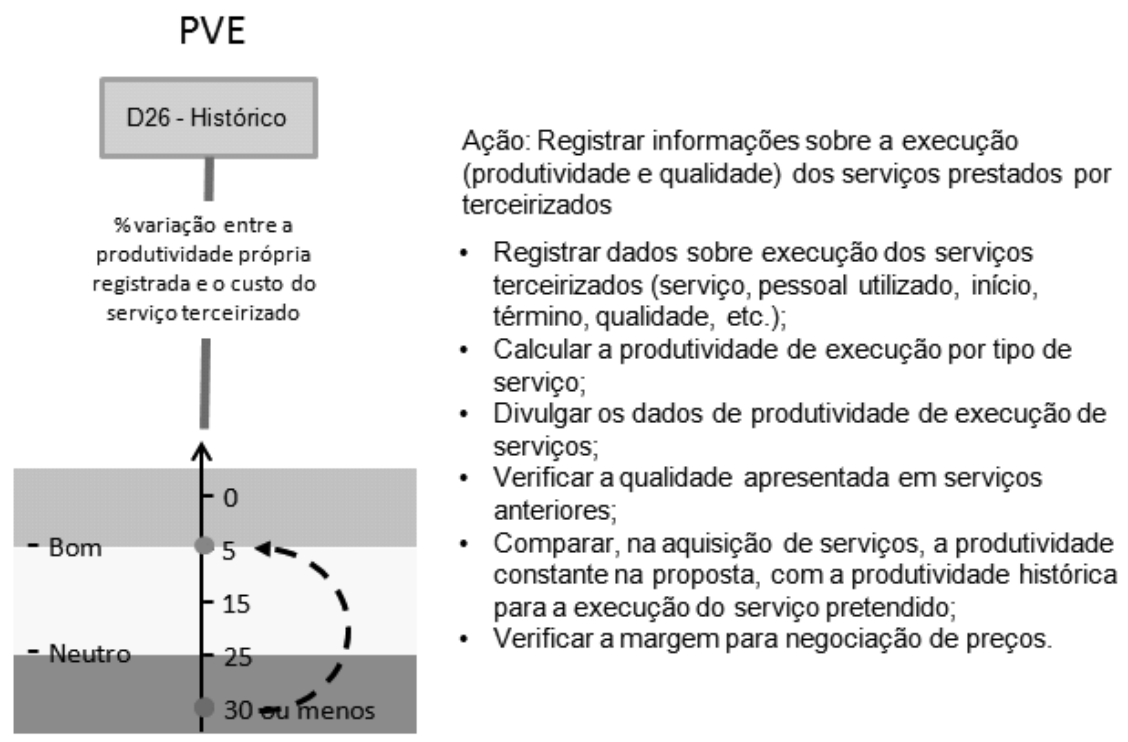

Figura 10 - Impacto do plano de ações no descritor do PVE Histórico

A comparação dos planos de ação permitiu ao decisor visualizar as consequências que a aplicação de cada um deles teria sobre a avaliação global do processo de orçamento de empreendimentos e o custo/benefício de cada um. Apesar de o Plano de Ações Geral (conjunto das ações de todos os planos somadas) apresentar o melhor custo por ponto obtido, o decisor elencou o Plano de Ações Produtividade como o mais plausível de ser aprovado pela diretoria da empresa, por apresentar um custo inferior e reflexos significativos na avaliação global.

Como pode ser verificado, todo o conhecimento gerado no decisor pela metodologia MCDA-C permitiu a ele identificar:

(a) os aspectos que podem ser objetos de ações;

(b) a prioridade com a qual esses aspectos devem ser tratados;

(c) as ações para promover o aperfeiçoamento; e

(d) a visualização do impacto ou consequência das ações, nos níveis operacional (PVE), tático (PVF) e estratégico (Global).

\section{Considerações finais}

Este trabalho relata o estudo de caso desenvolvido em uma construtora brasileira que objetivou o desenvolvimento de um modelo de apoio à decisão que permitiu identificar, mensurar e integrar os aspectos que influenciam os desvios de orçamento em seus empreendimentos, considerando a percepção do decisor quanto ao que é relevante no processo de orçar um empreendimento.

A aplicação do modelo no orçamento de um projeto dessa empresa permitiu visualizar o valor do desempenho global, proporcionando uma visão detalhada, em que cada aspecto relevante foi mensurado, e sua importância em relação ao todo, identificada.

A estruturação hierárquica do modelo permitiu o estabelecimento de visões estratégicas, táticas e operacionais.

O processo participativo de construção do modelo propiciou ao decisor conhecimento suficiente para que fossem estabelecidos planos de ações com vistas à melhoria do processo. Por meio do modelo, as consequências de cada ação puderam ser visualizadas e compreendidas pelo decisor, assim como o impacto delas sobre a avaliação global do processo, fornecendo os subsídios necessários para a tomada de decisão.

Assim, a metodologia MCDA-C atendeu aos objetivos propostos, gerando conhecimento no decisor sobre o contexto avaliado e propiciando condições para a estruturação de ações para a melhoria do desempenho da empresa no processo avaliado.

Todas as fases e passos da construção do modelo de avaliação foram legitimados pelo decisor. $\mathrm{O}$ modelo de avaliação desenvolvido neste trabalho propiciou à empresa e ao decisor um amplo conhecimento sobre o que é relevante no processo de orçar um empreendimento, criando condições para o estabelecimento de ações que conduzam à melhoria contínua desse processo.

Dessa forma, evidencia-se que a metodologia MCDA-C mostrou-se útil no processo de apoiar a atividade de orçamentação de obras em construção civil. Recomenda-se seu uso em outros contextos com o propósito de testar sua generalidade em 
situações semelhantes, observando-se, no entanto, que o modelo aqui apresentado é específico para a construtora estudada, e não se recomenda sua replicação em outros contextos, mesmo que semelhantes.

Como recomendação para trabalhos futuros, sugere-se que o contexto do problema seja analisado sob a ótica de outras empresas construtoras, a fim de avaliar o impacto que a visão de outros decisores trará sobre os critérios, escalas ordinais e cardinais e taxas de compensação, uma vez que a personalização do contexto pelos valores de um decisor específico traduz a principal limitação deste trabalho.

\section{Referências bibliográficas}

ASSOCIAÇÃO BRASILEIRA DE NORMAS TÉCNICAS. ISO 9001: sistemas de gestão da qualidade. 2000.

BANA E COSTA, C. A. et al. Decision Support Systems in Action: integrated application in a multicriteria decision aid process. European Journal of Operational Research, v. 113, n. 2, p. 315-335, 1999.

BANA E COSTA, C. A.; VANSNICK, J. C. Uma Nova Abordagem ao Problema da Construção de uma Função de Valor Cardinal: MACBETH. Investigação Operacional, v. 15, p. 15-35, jun. 1995.

BANAITIENE, N. et al. Evaluating the Life Cycle of a Building: a multivariant and multiple criteria approach. Omega-International Journal of Management Science, v. 36, n. 3, p. 429-441, jun. 2008.

BARZILAI, J. On the Foundations of Measurement. In: IEEE INTERNATIONAL CONFERENCE ON SYSTEMS, MAN AND CYBERNETICS, Tucson, 2001. Proceedings... Tucson: IEEE, 2001.p. 401-406.

BRASIL. MINISTÉRIO DAS CIDADES. Programa Brasileiro de Qualidade e Produtividade no Habitat. 2005. Disponível em: <http://www.cidades.gov.br/pbqp-h>. Acesso em: 10 nov. 2010.

CIOFFI, D. F.; KHAMOOSHI, H. A Practical Method of Determining Project Risk Contingency Budgets. Journal of the Operational Research Society, v. 60, n. 4, p. 565-571, apr. 2009.

COSTA, D. B. et al. Benchmarking Initiatives in the Construction Industry: lessons learned and improvement opportunities. Journal of

Management in Engineering, v. 22, n. 4, p. 158167, 2006.
DUTRA, A. et al. Incorporação da Dimensão Integrativa nos Processos de Avaliação do Desempenho Organizacional: um estudo de caso. Revista Contemporânea de Contabilidade, Florianópolis, v. 6, n. 11, p. 109-136, jan./jun. 2009.

EDEN, C.; JONES, S.; SIMMS, D. Messing About in Problems. R\&D Management, v. 15, n. 3, p. 255-255, 1985.

ENSSLIN, L. Notas de Aula. Disciplina de MCDA-C do Programa de Pós Graduação em Engenharia da Produção, Universidade Federal de Santa Catarina, Florianópolis, 2009.

ENSSLIN, L.; DUTRA, A.; ENSSLIN, S. R. MCDA: a constructivist approach to the management of human resources at a governmental agency. International Transactions in Operational Research, v.7, n.1, p. 79-100, 2000.

ENSSLIN, L. et al. Avaliação do Desempenho de Empresas Terceirizadas com o Uso da Metodologia Multicritério de Apoio à Decisão: construtivista. Pesquisa Operacional, v. 30, n. 1, p. 125-152, jan./abr. 2010.

ENSSLIN, L.; MONTIBELLER, N. G.; NORONHA, S. M. Apoio à Decisão: metodologias para estruturação de problemas e avaliação multicritério de alternativas. Florianópolis: Insular, 2001.

FAN, M.; LIN, N. P.; SHEU, C. Choosing a Project Risk-Handling Strategy: an analytical model. International Journal of Production Economics, v. 112, n. 2, p.700-713, abr. 2008.

FARRIS, J. A. et al. Evaluating the Relative Performance of Engineering Design Projects: a case study using data envelopment analysis. Ieee Transactions on Engineering Management, v. 53, n. 3, p. 471-482, ago. 2006.

HOFFMANN, V. E.; PROCOPIAK, J. A.; ROSSETTO, C. R. As Estratégias de Influência dos Stakeholders nas Organizações da Indústria da Construção Civil: setor de edificações em Balneário Camboriú, SC. Revista Ambiente Construído, Porto Alegre, v. 8, n. 3, p. 21-35, jul./out. 2008.

JACOMIT, A. M.; GRANJA, A. D. Análise Crítica da Aplicação do Custeio-Meta no Desenvolvimento de Empreendimentos de Habitação de Interesse Social. Revista Ambiente Construído, Porto Alegre, v. 10, n. 1, p. 143-162, jan./mar. 2010.

102 Azevedo, R. C.; Ensslin, L.; Lacerda, R. T. de O.; França, L. A.; González, C. J. I.; Jungles, A. E.; Ensslin, S. R. 
KAPLINSKI, O. Development and Usefulness of Planning Techniques and Decision-Making Foundations on the Example of Construction Enterprises in Poland. Technological and Economic Development of Economy, v. 14, n. 4, p. 492-502, 2008.

KEENEY, R. L. Value-Focused Thinking: a path to creative decisionmaking. London: Harvard University Press, 1992.

KEENEY, R. L.; RAIFFA, H. Decisions with Multiple Objectives: preferences and value tradeoffs. New York: John Wiley \& Sons, 1976.

KERN, A. P.; FORMOSO, C. T. A Model for Integrating Cost Management and Production Planning and Control in Construction. Journal of Financial Management of Property and Construction, v. 11, n. 2, p. 75-90, 2006.

KERN, A. P.; SOARES, A. C.; FORMOSO, C. T. O Custo Meta no Planejamento e Controle de Custos de Empreendimentos de Construção. In:ENCONTRO NACIONAL DE TECNOLOGIA NO AMBIENTE CONSTRUÍDO, 11., Florianópolis, SC, 2006. Anais... Florianópolis: Antac, 2006.

KOO, C. W. et al. Study on the Development of a Cost Model Based on the Owner's Decision Making at the Early Stages of a Construction Project. International Journal of Strategic Property Management, v. 14, n. 2, p. 121-137, 2010.

LACERDA, R. T. O.; ENSSLIN, L.; ENSSLIN, S. R. A Performance Measurement Framework in Portfolio Management: a constructivist case. Management Decision, v. 49, n. 4, p. 9-19, 2011 a.

LACERDA, R. T. O.; ENSSLIN, L.; ENSSLIN, S. R. A Performance Measurement View of IT Project Management. International Journal of Productivity and Performance Management, v. 60, n. 2, p. 132-151, 2011 b.

LIU, L.; ZHU, K. Improving Cost Estimates of Construction Projects Using Phased Cost Factors. Journal of Construction Engineering and Management, v. 133, n. 1, p. 91-95, 2007.

LOPES, O. C.; LIBRELOTTO, L. I.; AVILA, A. V. Orçamento de Obras. Florianópolis: Universidade do Sul de Santa Catarina, 2003.

MARCHIORI, F. F. Desenvolvimento de um Método para Elaboração de Redes de Composições de Custo para Orçamentação de Obras de Edificações. 237 f. 2009. Tese (Doutorado em Engenharia Civil) - Escola Politécnica, Universidade de São Paulo, São Paulo, 2009.
MARCHIORI, F. F.; UBIRACI, E. L. D. S. A Interação do Orçamento com o Departamento de Suprimentos em Empresas de Construção. In: ENCONTRO NACIONAL DE TECNOLOGIA NO AMBIENTE CONSTRUÍDO, 11., Florianópolis, SC, 2006. Anais... Florianópolis: Antac, 2006.

MONTIBELLER, G. et al. Reasoning Maps for Decision Aid: an integrated approach for problemstructuring and multi-criteria evaluation. Journal of the Operational Research Society, v. 59, p. 575-589, 2008.

MORAES, L. et al. The Multicriteria Analysis for Construction of Benchmarkers to Support the Clinical Engineering in the Healthcare Technology Management. European Journal of Operational Research, v. 200, n. 2, p. 607-615, 2010.

OTERO, J. A. Uso de Modelos Paramétricos em Estimativas de Custo para Construção de Edifícios. In: ENCONTRO NACIONAL DE ENGENHARIA DE PRODUÇÃO, 18., Niterói, RJ, 1998. Anais... Niterói, RJ, 1998.

POLLACK-JOHNSON, B.; LIBERATORE, M. J. Incorporating Quality Considerations Into Project Time/Cost Tradeoff Analysis and Decision Making. Ieee Transactions on Engineering Management, v. 53, n. 4, p. 534-542, nov. 2006.

ROY, B. Decision Science or Decision-Aid Science? European Journal of Operational Research, v. 66, n. 2, p. 184-203, 1993.

ROY, B. Multicriteria Methodology for Decision Aiding. Dordrecht: Kluwer Academic Press, 1996.

TAS, E.; YAMAN, H. A Building Cost Estimation Model Based on Cost Significant Work Packages. Engineering, Construction and Architectural Management, v. 12, n. 3, p. 251-263, 2005.

TASCA, J. E. et al. An Approach for Selecting a Theoretical Framework for the Evaluation of Training Programs. Journal of European Industrial Training, v. 34, n. 7, p. 631-655, 2010.

UNIEMP. Fórum Permanente das Relações Universidade-Empresa. 2010.

WALKER, A. Project Management in Construction. London: Blackwell Publishing, 2007.

WINTER, M.; CHECKLAND, P. Soft Systems: a fresh perspective for project management. In: Civil Engineering. Proceedings... London: ICE, 2003. v. 156, n. 4, p. 187-192. 
YANG, J.-B.; PENG, S.-C. Development of a Customer Satisfaction Evaluation Model for Construction Project Management. Building and Environment, v. 43, n. 4, p. 458-468, 2008.

ZAMCOPÉ, F. C. et al. Modelo para Avaliar o Desempenho de Operadores Logísticos: um estudo de caso na indústria têxtil. Gestão \& Produção, v. 17, n. 4, p. 693-705, 2010.
ZENG, J.; AN, M.; SMITH, N. J. Application of a Fuzzy Based Decision Making Methodology to Construction Project Risk Assessment. International Journal of Project Management, v. 25 , n. 6 , p. 589-600, 2007.

Revista Ambiente Construído Associação Nacional de Tecnologia do Ambiente Construído Av. Osvaldo Aranha, $99-3^{\circ}$ andar, Centro Porto Alegre - RS - Brasil CEP $90035-190$

Telefone: +55 (51) 3308-4084 Fax: +55 (51) 3308-4054 www.seer.ufrgs.br/ambienteconstruido E-mail: ambienteconstruido@ufrgs.br 